\title{
Cytological versus Histopathological Examination in Lesions of Cervix, taking histopathology as a Gold Standard
}

\author{
ANAM ILYAS ${ }^{1}$, AMAN-UR-REHMAN², MUHAMMAD IKRAM ${ }^{3}$, GOHAR ALI KHAN4, MOMINA JEHANGIR KHAN ${ }^{5}$, ZAIB ${ }^{6}$ \\ ${ }^{1}$ Histopathology Department, Shaikh Zayed Hospital, Lahore \\ ${ }^{2}$ Histopathology Department, Shaikh Zayed Hospital, Lahore \\ ${ }^{3}$ Professor of Obstetrics \& Gynaecology Department, Shaikh Zayed Hospital, Lahore \\ ${ }^{4}$ Histopathology Department, Shaikh Zayed Hospital, Lahore \\ ${ }^{5}$ Histopathology Department, Azra Naheed Medical College, Lahore \\ Correspondence to Anaml lyas, Email: anam.ilyas196@gmail.com, Phone \#.03227280508
}

\begin{abstract}
Background: Malignancy of cervix is the major health burden in South Asia including Pakistan. PAP smear is the screening test for its early detection. To find out the specificity and sensitivity of the system called as Bethesda system, the correlation of cytological findings with histopathology, with histopathological examination as the golden standard.

Aim: To find out the cytological utility in diagnosing different pathologies of cervix, to assess and infer the epithelial lesions cases and to correlate cytology findings with its consequent follow-up biopsies.

Methods: This study was carried out taking 150 PAP smears of women coming to gynecological OPD ofShaikh Zayed Hospital Lahore from September 2020 to February 2021. There correlation with subsequent follow-up histology sections by using 2001 revised Bethesda System.Different factors analysis which were causing inconsistencies was done.

Results:The overall sensitivity of PAP smear is $86.94 \%$, specificity $57.14 \%$, positive predictive value $86.94 \%$, negative predictive value $57.14 \%$ and accuracy $80 \%$ in detecting low/high grade lesions and malignancy. Keywords: Bethesda system,Cervix cytology findings; Histopathological findings.
\end{abstract}

\section{INTRODUCTION}

About ten lac women die around the globe in a year. Cancer of cervix is second most common among malignancies of female after breast carcinoma. This morbidity and mortality are reduced when diagnosed timely. The Bethesda system reporting cytology of cervix and diagnosing it, that is the unchanging system to report\&provide a useful and efficient way of communication among cytopathologists\& refer towards otherdoctors. The physicians incorporated conventional, old Papanicolaou (PAP) smear from the nineteenth century, whichwas being used widelyand was brought into widespread use in the 1950s for detecting female genital tractmalignancy,mainly carcinoma cervix and its precursor lesions. ${ }^{[1]}$ Cytology of cervix (PAP smears) isprimarily done as a screening test for women which undergototal hysterectomy due to reproductive tract malignancy or, a small ratio, who have a recent pathology affecting vagina. ${ }^{[2,3]}$. The study that was carried out currentlywhich was to study the effectiveness of cytology of vaginal and cervix to diagnose neoplastic and pre- neoplasticcervical pathologies.

\section{Aims and Objectives}

- To correlate findings of cytology with subsequent biopsy sections.

- To assess and interpret the epithelial lesion cases with reference to the Bethesda2001 classification system.

- Enquiry of multiple factors which are causing inconsistencies in final ultimate diagnosis.

- $\quad$ An assistance to control the internal quality.

Received on 03-02-2021

Accepted on 23-05-2021

\section{MATERIALS AND METHODS}

With the help of Conventional Papanicolaou (PAP) method, we took smearsfrom women aged above 25 years presenting in gynaecological OPD, Shaikh Zayed Hospital Lahore over a period from September 2020 to February 2021by gynaecologist. Personal biodata \& clinical symptomatic history like age, religion, parity, tobaccouse, HIV status,socio-economic status, presenting complaints, any past therapy (surgery /hormonal /radiotherapy) taken for cervical carcinoma was taken and entered in a welldesigned performa. The age of patients ranged from 25 to 70 years and parity between 0 to $>5$. All the smears were taken from transformation zone (squamo-columnar junction) of cervix by scrapping it with the help of high vaginal swab stickrotate the stick at 360 degrees and directlyfixed in ethanol fixative for 30 minutes. Then they sent them along with completely filled request form for further processing to cytology lab. In the lab,staining of fixed slides were done by Papanicolaoustain. The follow up biopsies were taken of the smears with abnormality in epithelium. Histology sections staining were done with the routine Hematoxylin \& Eosin stain. Cytopathological examination and histopathological correlation were done and rate of concordance was calculated for each category. All PAP smears were reported as per The Bethesda 2001 classification system\& for histological findings WHO 2003 classification system was used.

All the cytopathological lesions of cervix were classified as per guidelines of 2001 Bethesda system of cytology of cervix ${ }^{4,11,13}$.

Negative for any intraepithelial lesion or malignancy (NILM)

(When there is no cytological finding of carcinoma/ neoplasiais found in smears) 
Organisms: Bacteria Trichomonasvaginalis, shows shift in flora which is consistent with bacterial vaginosis

- Fungal organisms morphology favor Candida species, Bacteria which morphologically resemble with Actinomyces spp.

- Cytological changeswhichfavor herpes simplex virus2.2Other

- Findings of Endometrial cells (in a women greater than 40years) (indicate if it is "negative for squamous intraepithelial lesion")

2.5 Abnormalitiesin Epithelial Cells

\section{In Squamous Cells}

- Atypiasquamoid cells of undetrmined significance (ASC-US)

- Low-grade squamous intrepitheliallession (LSIL) (focusing: Humain Papiloma Virus / CIN 1)

- High-grade squamous intrepitheliallession (HSIL) (focusing: moderated and severed dyspasia, CIN 2 and CIN 3; Carcinoma in situ)

- Squamos cell carcinoma

\section{Gladular Cells}

- Atypia (Endo-cervical cells / Endo-metriod cells /Glandular cells (NOS or specify in comments))

- $\quad$ Atypia cells(glandular cells / Endo-cervical cells which favors malignancy, and Endo-cervical adeocarcioma in situd)

- Adeocarcinoma (Endometrial, Edo-cervicl, Etrauerine, Nootherisespecifie (NoS))

In present study Statistical Analysis says, thatgenerally it was $57.14 \%$ specific, $86.95 \%$ sensitive, with $86.95 \%$ positive predictive value (PPV), $57.14 \%$ negative predictive value (NPV) and $80 \%$ Accurate

\section{Calculation:}

Specificity $=\{D / D+B\} \times 100=57.14 \%$

Sensitivity $=\{A / A+C\} \times 100=86.95 \%$

Negative predictive value (NPV) $=\{D / D+C\} \times 100=57.14 \%$ Positive predictive value (PPV) $=\{A / A+B\} \times 100=86.95 \%$ Accuracy $=\{A+D / A+B+D+C\} \times 100=80 \%$

$[A=$ Trupostivcass $(T P)=20, B=$ Falspostivcass $(F P)=3, C=$ Falenegaivcses $(F N)=3, D=$ Tenegtivcse $(T N)=4]$

\section{RESULTS}

The cytopathological results and subsequent histopathological results were examined and studied in all epithelial cell lesions. Histopathologywas considered superior and was taken as the golden standard. The classification was done according to the system named as 2001 Bethesda classification system which was stated previously and the histopathological results were categorized as per WHO 2003 classification system ${ }^{5}$. Total 150 smears were included. Among these, 102 out of 150 smears were non-malignant/inflammatory, 18cases were not satisfactory and in the residual cases, 30 revealed abnormalities in epithelial cells. All lesions of cervix with abnormalities in epithelial cells, clinicians were guided to takebiopsy from the cervix for confirming the diagnosis. The overall rate of concordance was calculated. Also,the concordance rate was analyzed for allpathologic entities individually, according to the guidelines of Bethesda 2001 System. Squamous cell carcinoma was the most prevalent neoplastic pathology. All these pathologic lesions are classified as under in (Table 1).

Table 1: Categorization ofepithelial cell lesions of cervix according to cytopathological and histopathologicalexamination

\begin{tabular}{|l|c|c|}
\hline \multirow{2}{*}{$\begin{array}{l}\text { Epthelial cell lesions - PA Psmercytopathogical } \\
\text { results ( } \mathbf{n = 1 5 0 )}\end{array}$} & Epthelial cell lessions - PA Psmer histopathological results (n=30) \\
\cline { 2 - 3 } & $\mathbf{C I N ~ I ~}$ & CIN II/III \\
\hline Atypia cell of undetrminsignifican (6) & 6 & - \\
\hline Atypical squamous cell - H (4) & 5 & - \\
\hline Low grad squams cell carcinoma in situ (6) & 6 & - \\
\hline Hih grad squams cell carcinoma in situ (6) & 0 & 7 \\
\hline Squams cell carcinoma (8) & 0 & 5 \\
\hline Non- neoplastic (102) & - & 1 \\
\hline
\end{tabular}

Generally, this study was $76 \%$ concordantand $24 \%$ discordant (Table 2 )

Table 2: The rate of concordance

\begin{tabular}{|l|l|l|}
\hline Cases & $\mathbf{n}$ & \%age \\
\hline Discordance rate & 9 & 30 \\
\hline Concordance rate & 21 & 70 \\
\hline Total & 30 & 100 \\
\hline
\end{tabular}

\section{DISCUSSION}

This study is $70 \%$ concordant with other such studies, for example. Study carried out by $\mathrm{Nawaz}^{6}$ at Aga Khan University, Pakistan showed $74 \%$ cocorancrates. The other studies for exampleRasbridge ${ }^{7}$, Yeoh ${ }^{8}$ \& Saha " $s^{9}$ \& had cocordace rats as $81.2 \%, 52 \%$ and $60 \%$ correspondingly.

In this study, out of the 9 conflicting cases, 5cases wereundiagnosed on cytopathology, 3 caes were diagnosed as non- neoplastic and ASCS, AC-H \& LSLwere the diagnoses in 1 case each. The majorcause for underdiagnosing was low cellularity with haemorrhage/ inflammation concealing background. Actual diagnosis was made when such smears were repeated. Biopsy helped in these cases. Some smears showed fixation and airdryingerrors and sothe diagnosis was hindered. In studies by $\mathrm{Yeoh}^{7}$ \& Saha ${ }^{8}$,a mainfactor of false negative rate was due to preparation and samplingerrors. Thus, to conclude in order to lessen false negative rate, repeat smears should be takenat regular intervals. With three normal successive smears performed annually the Error rate is almost minimal.

\section{CONCLUSION}

The present research gives a clue to assess the intenalqulity of cytological reorting. For the diagnosis of high-grade lesions and malignancies, the PAP smer is very specific, sensitive and has a good positive predictive vale. The sensitivity can be amplified by satisfactory sampling and minimizing practicalproblems like fixation andair-drying 
errors. The variation can be lessened by following sampling adequacy criteria of the Bethesda system Thefixation and sampling artefacts can be efficientlyminimized by appropriateorganization and conversingerrors during smear preparation with the clinicians

Source of support: nil

Conflict of interest: None

Conflict of interest notification page:All authors have no conflict of interest to any information or data in this study.

\section{REFERENCES}

1. Koss LG. The Papanicolaou test for cervical cancer detection.A triumph and a tragedy. JAMA. 1989; 261:737743.

2. Saslow D, Runowicz CD, Solomon D, et al. American Cancer Society Guideline for the Early Detection of CervicalNeoplasia and Cancer. J Low Genit Tract Dis.2003; 7:67-86. Kuntal Patel et al/ Histopathological Vs. cytological findings in cervical lesions 533 IJBAR (2016) 07 (11) www.ssjournals.com

3. ACOG Practice Bulletin No. 109: cervical cytology screening. Obstet Gynecol.2009; 114:1409-1420.

4. Papanicolaou GN (1928) New cancer diagnosis proc 3rd Race Betterment conference Battle Greek, Michigan, 528530 .
5. American Cancer Society Guidelines for the Early Detection of Cancer, 2003; 53(1): 27-43.

6. Nawaz FH, Aziz AB, Perwez S, Rizvi JH. Prevalence of abnormal Panicolaou smears and cytohistological correlation. A study from Aga Khan University hospital, Pakistan. Asia-Pacific Journal of clinical oncology 2005; 1: 128- 132.

7. Saha R, Thapa M. Correlation of cervical cytology with cervical histology. Kathmandu Univ Med J (KUMJ) 2005; 3: 222-224.

8. Yeoh GPS, Chan KW. The accuracy of Panicolaousmear prediction: Cytohistological correlation of 283 cases. HKMJ1997; 3: 373-376.

9. One year audit by Simon (1995) RasbridgeActacytologica 39: 648-651.

10. Jain Vaishali, Vyas AS. Cervical Neoplasia-CytoHistological Correlation (Bethesda System) A Study of 276 Cases. J CytolHistol2010; 1:106. doi:10.4172/2157- 7099.1000106

11. Crothers BA. The Bethesda System 2001: update on terminology and application. ClinObstetGynecol2005; 48: 98107.

12. Gupta S, Sodhani P. Why is high grade squamous intraepithelial neoplasia under-diagnosed on cytology in a quarter of cases? Analysis of discrepant cases" Indian J Cancer 2004; 41: 104-108.

13. Dehner LP. Cervicovaginal cytology, false negative result and standard of practice. Am J ClinPathol1993; 99: 45-47. 